\title{
CONTROLE PÚBLICO DA EDUCAÇÃO E REGISTRO DE DIPLOMAS DE CURSOS SUPERIORES
}

Horácio Wanderlei Rodrigues*

\section{RESUMO}

Este artigo analisa a constitucionalidade do direito de concessão do registro de qualificações para cursos de licenciatura (graduação e pós-graduação) exclusivamente às universidades. Para atingir o objetivo, o trabalho foi dividido em três fases, em cada uma um aspecto do objeto estudado. Na primeira realizou-se uma análise dos princípios incluídos na Constituição Federal em relação ao ensino superior, em especial, os princípios da liberdade de ensino e de controle público da educação. Na seguinte é avaliada, à luz da Constituição, a autoridade legislativa para emitir a educação regras gerais nacionais. Na terceira e última, analisamos a atribuição de modo que apenas o registro de infra universidades de diplomas de ensino superior.

Palavras-chave: a liberdade do ensino. Controle da educação pública. A autonomia universitária. Certificados de matrícula.

\section{INTRODUÇÃo}

A educação é objeto permanente de preocupação de todos os povos. E para que essa preocupação gere políticas públicas adequadas, o tratamento que ela recebe nas constituições, em especial em nível dos princípios, deve ser objeto constante de estudos e análises. Nesse contexto, este artigo contém uma análise jurídica, centrada em especial na Constituição Federal, de uma dicotomia (ou falsa dicotomia) presente no Direito Educacional brasileiro, qual seja, a presença, de um lado, da liberdade de ensinar, garantida à iniciativa privada, e de outro, a existência de controle público, com o objetivo de responder uma questão específica: podem as IES não caracterizadas como universidades registrarem seus próprios diplomas, considerando o princípio constitucional da liberdade de ensinar?

Para atingir o objetivo proposto, o trabalho foi dividido em três momentos, procurando, em cada um deles, analisar um aspecto do objeto estudado. No primeiro realiza-se uma análise dos princípios inseridos na Constituição Federal relativamente à educação superior, em especial os princípios da liberdade de ensinar e do controle público da educação. Na sequência aprecia-se, à luz da constituição, a competência legislativa para a edição das normas gerais da educação nacional. Em um terceiro e último momento analisa-se a atribuição infraconstitucional para que apenas as universidades registrem os diplomas dos cursos superiores.

\section{OS PRINCÍPIOS CONSTITUCIONAIS RELATIVOS À EDUCAÇÃO SUPERIOR}


A Constituição Federal de 1998 trata especificamente da educação em seu Titulo VI (Da ordem social), Capítulo III (Da educação, da cultura e do desporto), Seção I (Da educação). Em seu artigo 205, contém no que tem importância para este trabalho, a indicação dos responsáveis diretos e dos colaboradores do processo de ensino-aprendizagem. É o seu texto:

Art. 205. A educação, direito de todos e dever do Estado e da família, será promovida e incentivada com a colaboração da sociedade, visando ao pleno desenvolvimento da pessoa, seu preparo para o exercício da cidadania e sua qualificação para o trabalho.

Esse dispositivo da Constituição Federal adota um sentido amplo de educação, atribuindo o dever de educar à família e ao Estado. A sociedade, no âmbito do qual estão situadas as instituições privadas de ensino, aparece apenas como colaboradora.

No artigo 206, o texto constitucional enumera os princípios segundo os quais deve ser ministrada a educação. Destacam-se a seguir apenas aqueles que possuem interesse para o objeto central deste texto.

\footnotetext{
Art. 206. O ensino será ministrado com base nos seguintes princípios:

$[\ldots]$

II - liberdade de aprender, ensinar, pesquisar e divulgar o pensamento, a arte e o saber;

III - pluralismo de idéias e de concepções pedagógicas;

[...]

VII - garantia de padrão de qualidade;

$[\ldots]$.
}

Os incisos não transcritos dizem respeito ao acesso e permanência na escola (sem diferenciação entre pública e privada), e a gratuidade do ensino público, sua gestão democrática e ao ingresso, valorização e remuneração dos seus profissionais. Como se percebe, não tratam de temas de interesse para a análise proposta para este trabalho.

Já os três incisos em destaque, que constituem normas orientadoras fundamentais do Direito Educacional brasileiro, estabelecem, no que interessa ao tema em estudo:

a) nos incisos II e III, de forma geral, as idéias de liberdade e pluralismo, como inerentes ao processo de ensino-aprendizagem e, portanto, à sua organização por parte das IES; ou seja, o respeito à ordem constitucional implica em um processo de ensino-aprendizagem baseado na liberdade e no pluralismo, colocando para as IES a necessidade do respeito às diferenças e a flexibilidade de seus projetos; e

b) a necessidade de que as IES, no exercício de suas atividades mantenham um determinado padrão de qualidade.

Nesse sentido, o conteúdo desses três dispositivos constitucionais possui preponderantemente objetivos no plano pedagógico; adquirem caráter administrativo como decorrência, com a finalidade de garanti-los. 
Cabe ressaltar, ainda em nível constitucional, no que se refere especificamente às IES privadas, o texto do artigo 209 da Constituição Federal, que estabelece:

Art. 209. O ensino é livre à iniciativa privada, atendidas as seguintes condições:

I - cumprimento das normas gerais da educação nacional;

II - autorização e avaliação de qualidade pelo Poder Público.

Esse dispositivo contém a previsão constitucional de que a iniciativa privada possui liberdade de ensinar, mediante o atendimento de determinadas condições, quais sejam:

a) o cumprimento das normas gerais que tratam da educação. Destaquese a utilização no artigo 209 da Constituição Federal das expressões atendidas e cumprimento, frente às quais parece não existir possibilidade de não atendimento de qualquer mandamento contido nas normas gerias da educação, a não ser que atinjam outra norma constitucional;

b) a autorização e avaliação pelo poder público, como instrumentos de verificação do atendimento dos princípios gerais da educação contidos em especial no artigo 206 do texto constitucional, com destaque especial para a garantia de padrão de qualidade.

Isso significa que o Poder Público tem de garantir, de um lado, flexibilidade suficiente para que as IES possam, nas suas propostas pedagógicas, realizar os mandamentos constitucionais e, de outro, que o exercício da liberdade de ensinar possui como limites, também fixados pelo Poder Público, os padrões de qualidade a serem exigidos mediante processos avaliativos oficiais, bem como as demais determinações organizacionais e administrativas contidas nas normais gerais da educação nacional, respeitados os direitos garantidos pela Constituição Federal.

Ou seja, a Constituição Federal contém permissão para que IES privadas ensinem ${ }^{1}$, mas mantém com o poder público ${ }^{2}$ o controle de qualidade, através de mecanismos de autorização e de avaliação periódica ${ }^{3}$ e de organização, através das demais normas gerais da educação nacional.

Relativamente à condição de que haja o cumprimento das normas gerais da educação nacional, deve-se entender a necessidade de cumprimento das Leis que estabelecem as Diretrizes e Bases da Educação Nacional ${ }^{4}$, contidas não apenas na denominada LDB, mas no conjunto normativo atinente especificamente à educação e que tenha por objetivo instrumentalizar os princípios previstos constitucionalmente, criar os mecanismos de avaliação, organizar e administrar o sistema educacional como um todo.

Destaque-se que a liberdade contida no artigo 209 caput é para ensinar. É, portanto uma liberdade preponderante pedagógica. Busca permitir que a iniciativa privada possa exercer essa atividade, sob a supervisão do Estado, que é quem detém, juntamente com a família, o dever de educar; à sociedade cabe, no processo educacional, a colaboração. ${ }^{5}$ 
De forma resumida pode-se afirmar que o princípio inserido no texto constitucional, da liberdade de ensinar, não é absoluto, pois pressupõe o atendimento das exigências também constitucionais de (a) garantia de padrão de qualidade (aferida através dos processos de autorização e avaliação estabelecidos pelo poder público) e de (b) cumprimento das normas gerais da educação nacional.

Ou seja, para o exercício dessa liberdade duas condições são colocadas: (a) manutenção de padrão de qualidade, ficando a cargo do Poder Público, através do Ministério da Educação, o papel de exercer o acompanhamento e a verificação através de mecanismos de avaliação; e (b) cumprimento das normas gerais da educação brasileira estabelecidas expressamente na própria Constituição Federal e nas Leis que estabelecem as Diretrizes e Bases da Educação Nacional.

\section{EDUCACIONAL \\ 3 A COMPETÊNCIA PARA EDITAR NORMAS EM MATÉRIA}

No que se refere às Diretrizes e Bases da Educação Nacional, a competência legislativa é privativa da União, tendo em vista o que determina o artigo 22, inciso XXIV da Constituição Federal. Já no que se refere a legislar com a finalidade de proporcionar os meios de acesso à educação e sobre a educação e o ensino em geral (ou seja, com exceção daqueles casos em que a competência é privativa) essa competência é concorrente com os Estados, o Distrito Federal e os Municípios, segundo o que dispõe o texto constitucional em seu artigo 23, incisos V e IX, respectivamente.

Quando se tratar de competência concorrente, visando assegurar o princípio federativo, a União deve definir as normas gerais, cabendo aos demais entes federados, a elaboração das normas específicas. ${ }^{6}$ Nesse sentido, o artigo 211 do texto constitucional estabelece que a União, os Estados, o Distrito Federal e os municípios organizarão seus sistemas de ensino em regime de colaboração.

A legislação infraconstitucional estabelece no artigo $8^{\circ}$, parágrafo $1^{\circ}$, da Lei n.. 9.394/96 (LDB), que é da União a função normativa, quando se tratar da organização da educação nacional (entenda-se aqui a competência para a elaboração das normas gerais da educação nacional).

Nos casos em que as Instituições de Ensino Superior - sejam públicas ou privadas - pertencerem ao sistema federal de educação, competirá à União não apenas definir as normas gerais, mas todas as normas a ela aplicáveis, em cumprimento ao que dispõe o artigo 211, parágrafo $1^{\circ}$ do texto constitucional. As IES privadas, por integrarem o sistema feral de educação, estão submetidas unicamente à legislação federal.

Deve-se ainda destacar que o poder de legislar em matérias de competência da União, segundo o artigo 44 da Constituição Federal, é exercido pelo Congresso Nacional. Essa situação decorre também do próprio princípio da separação de poderes, contido no artigo $2^{\circ}$ da Constituição Federal. Significa que não havendo 
autorização constitucional expressa, a competência legislativa - criação e extinção de direitos - pertence ao Congresso Nacional, cabendo ao Poder Executivo, em nível normativo, apenas a criação dos mecanismos necessários à sua efetivação e ao Poder Judiciário a sua interpretação e aplicação, quando ocorrerem conflitos. ${ }^{7}$

Retornando à competência legislativa e, como decorrência, à identificação de quais são as normas gerais da educação nacional, pode-se afirmar que essas estão inseridas naqueles conjuntos normativos oriundos do parlamento ${ }^{8}$. Ou seja, elas devem ser buscadas na Constituição Federal e nas leis. No plano infraconstitucional estão inseridas fundamentalmente: (a) na Lei n.o 9.394/96 (LDB); (b) na Lei $n .$. 4.024/61 com a redação que Ihe foi dada pelas Leis n.ㅇ 9.131/95 e $n .0$ 10.861/2004 (cria o CNE e define suas competências); (c) na Lei $n .-10.861 / 2004$, que busca atender às exigências constantes dos artigos 206, inciso VII, e 209, inciso II da Constituição Federal (cria o SINAES); e (d) na Lei n.- 10.172/2001, que estabelece o Plano Nacional de Educação, expressamente previsto no artigo 214 da Constituição Federal.

Mas também podem ser encontradas em outras legislações que regulamentam aspectos específicos da questão educacional, regra geral em cumprimento a uma determinação da própria Constituição Federal ou da LDB; dentre essas cabe destacar: (a) a Lei n.. 9.795/99, que trata da educação ambiental, tema previsto no artigo 225, parágrafo $1^{\circ}$, inciso VI, da Constituição Federal; (b) a Lei n.. 9.536/97, que regulamenta as transferências coercitivas de servidores públicos, prevista no artigo 49, parágrafo único da LDB; (c) os artigos 22 da Lei $n . .-10$ $.741 / 2003$ (Estatuto do Idoso) e artigos 53 a 58 da Lei n.. 8.842/1994 (Estatuto da Criança e do Adolescente), considerando o disposto nos artigos 227 e 230 da Constituição Federal; e (d) a Lei , que trata dos estágios.

Em sentido contrário, não estão as normas gerais da educação contidas em decretos, resoluções e portarias; essas normas são apenas instrumentos da administração pública para regulamentar as normas gerais, mas não podem modificá-las ou lhes negar aplicação e efetividade, tendo em vista o princípio constitucional da separação dos poderes (artigo $2^{\circ}$ da Constituição Federal) ${ }^{9}$ e a competência legislativa dele decorrente, bem como o respeito à hierarquia das normas (princípio maior para resolução de antinomias jurídicas).

Isso não significa que essas normas de Direito Educacional possam descumpridas, mas sim que a leitura constitucional impõe um critério hierárquico: primeiramente os princípios contidos no próprio texto da Lei Maior; posteriormente as normas gerais da educação nacional; apenas na seqüência se colocam os demais textos normativos. E, nesse sentido, as Leis que estabelecem as Diretrizes e Bases da Educação não podem sobrepor-se à Constituição; e nem as demais normas de Direito Educacional podem sobrepor-se a elas. ${ }^{10}$

\section{LIBERDADE DE ENSINAR, CONTROLE PÚBLICO DA EDUCAÇÃO E REGISTRO DE DIPLOMAS DE CURSOS SUPERIORES}


A Constituição Federal contém em seu texto, relativamente ao sistema educacional, dois momentos diversos que tratam da liberdade de ensinar:

a) como princípio pedagógico, constante do artigo 206, incisos II e III liberdade e pluralismo; e

b) como princípio organizativo, presente no artigo 209 e seus incisos, combinado com o artigo 205 e o artigo 206, inciso VII - liberdade de oferecimento pela iniciativa privada, desde que atendidas às exigências de cumprimento das normas gerais da educação nacional e a autorização e avaliação de qualidade pelo poder público.

Para a adequada compreensão do tema a que se destina essa seção é necessário em primeiro lugar estabelecer qual o sentido da expressão liberdade de ensinar contida nos artigos 206, inciso II, e 209, caput.

No inciso II do artigo 206 essa expressão liberdade está contida dentro de um contexto claramente pedagógico e não administrativo. O caput do artigo se refere aos princípios segundo os quais será ministrado o ensino, indicando entre eles a "liberdade de aprender, ensinar, pesquisar e divulgar o pensamento, a arte e o saber". (grifei). E mesmo que se deseje atribuir a ele também um conteúdo administrativo, esse estará restrito à atividade de ensinar (organização das atividades de ensino, pertinentes no sistema educacional a organização dos projetos pedagógicos e sua implementação) e não às atividades burocráticas das IES.

No artigo 209, caput, a expressão livre (e não liberdade) está contida em um contexto de organização do sistema educacional. Sendo a educação dever do Estado (e da família), a ser promovida e incentivada com a colaboração da sociedade, o regramento atinente à participação da iniciativa privada tem de ser entendida nesse contexto. E nesse contexto o Estado tem o dever, e a sociedade onde está situada a iniciativa privada - colabora. Se o Estado é que possui o dever, compete a ele definir a regras segundo as quais a sociedade colabora.

Entendido claramente esse contexto, a expressão livre não pode entendida como a plena liberdade de organização e administração da IES privadas. A expressão livre utilizada pelo constituinte possui o sentido de que à iniciativa privada também está deferida a autorização para a prestação de serviços educacionais em colaboração com o Poder Público. Mesmo o disposto na parte final do inciso III do artigo 206 do texto constitucional, ao estabelecer entre os princípios com base nos quais será ministrado o ensino, a coexistência de instituições públicas e privadas, não elimina essa interpretação; pelo contrário, a confirma. A Constituição refere-se à co-existência; portanto a sociedade, através das IES privadas pode oferecer serviços educacionais, ou seja, esses não lhe podem ser proibidos - mas seu oferecimento também não lhe é obrigatório, o que ocorre apenas com o Estado.

Corroboram essa interpretação a enumeração pelo constituinte - nos incisos I e II do artigo 209 - de duas condições a serem atendidas para o oferecimento desses serviços, quais sejam (a) o cumprimento das normas gerais da educação nacional, e (b) a autorização e a avaliação de qualidade por parte do Poder Público. Essas condições já foram objeto de análise na seção anterior, não sendo necessário repetir aqui o que já foi dito. 
Além desses elementos até aqui enumerados, outro ainda merece destaque: a atribuição de autonomia às universidades ${ }^{11}$. Fosse a expressão livre, contida no artigo 209, compreendida no sentido amplo, de liberdade pedagógica, organizacional e administrativa, nenhum sentido teria a atribuição de autonomia às universidades, contida no artigo 207, pois se estaria então, através desse dispositivo, reduzindo o direito concedido pelo artigo 209 à todas as IES privadas.

Retomando agora a condição presente no inciso I do artigo 209, de cumprimento das normas gerais da educação nacional, buscar-se-á oferecer uma resposta ao problema inicialmente colocado, qual seja: podem as IES não caracterizadas como universidades registrarem seus próprios diplomas, considerando o princípio constitucional da liberdade de ensinar?

De acordo com a exigência contida no inciso primeiro do artigo 209 da Constituição Federal, ${ }^{12}$ todas as IES privadas (inclusive as universidades) têm a obrigação de cumprir as normas gerais da educação nacional, ou seja, obedecer ao contido nas normas educacionais oriundas do parlamento. Isso porque a Constituição Federal não autoriza o Poder Público a negar arbitrariamente o direito de ensinar, mas o condiciona ao atendimento das exigências expressamente enumeradas.

Sobre diplomas, a exigência de que sejam registrados para possuírem validade nacional, bem como a definição de quem pode registrá-los, estão contidas na Lei n.ำ 9.394/1996 (LDB), artigo 48 e seu parágrafo 1ํ․
Art. 48. Os diplomas de cursos superiores reconhecidos, quando registrados, terão validade nacional como prova da formação recebida por seu titular.
$\S 1^{\circ}$ Os diplomas expedidos pelas universidades serão por elas próprias registrados, e aqueles conferidos por instituições não-universitárias serão registrados em universidades indicadas pelo Conselho Nacional de Educação.
$[\ldots]$.

A LDB, Lei Federal editada pelo Congresso Nacional posteriormente à Constituição de 1988, é, sem nenhuma dúvida, o principal diploma legal que dispõe sobre as normas gerais da educação nacional. Nesse sentido, seu cumprimento é condição para o funcionamento de qualquer IES privada, segundo o que dispõe o inciso I do artigo 209 do texto constitucional.

Portanto, em uma primeira análise, é indiscutível a exigência de que as IES não universitárias necessitam registrar os diplomas por ela conferidos para que os mesmos tenham validade nacional como prova da formação recebida pelo egresso, e que esse registro deve ser realizado por uma universidade.

Relativamente à definição de quais universidades podem executar a atividade de registro, estabelece a LDB que serão aquelas indicadas pelo CNE. O CNE, em seu Parecer CNE/CES n. ${ }^{\circ}$ 165/2007, que trata do registro de diplomas expedidos por instituições não universitárias, aponta que: 
Art. 1‥ Os diplomas dos cursos de graduação e seqüenciais de formação específica expedidos por instituições não-universitárias serão registrados por universidades credenciadas, independentemente de autorização prévia deste Conselho.

Esse dispositivo em nada altera a obrigação trazida pela LDB - e nem poderia fazê-lo. Entretanto ele deixa às IES não universitárias a escolha da universidade na qual realizarão o registro, dentre aquelas credenciadas pelo CNE - não é mais necessário que essas instituições solicitem autorização a esse Conselho para que o mesmo indique especificamente a Universidade encarregada do registro dos diplomas daquele IES.

Uma possível alegação de que a autorização do registro dos Certificados dos Cursos de Especialização por parte das IES não universitárias seria contraditória com essa exigência, podendo ser utilizado como argumento para a autorização do registro dos diplomas também não prospera. A situação das especializações é anômala na legislação educacional brasileira - são elas os únicos cursos integrantes do ensino superior que não precisam de autorização expressa e que não passam por avaliação periódica de qualidade. Além disso, as especializações, muito mais próximas da extensão em sua caracterização, não dão direito a diploma, mas a simples certificado, documento legal de conteúdo e forma distintos dos diplomas.

Resta, entretanto, ainda uma última análise a ser realizada: a da inconstitucionalidade da norma estabelecida na LDB. Em uma leitura bastante objetiva, é possível afirmar que a definição de quem pode e de quem não pode registrar os diplomas não possui nenhum elemento que possa levar à arguição de sua inconstitucionalidade, visto que essa exigência, de cunho administrativo não atinge de nenhuma forma os princípios constitucionais relativos à educação.

Como foi visto, o princípio da liberdade de ensinar (Constituição Federal, art. 206, inc. II) é um princípio pedagógico, voltado à permitir o pluralismo de idéias e o respeito à diferença. Não é por acaso que ele está colocado no texto constitucional no mesmo dispositivo que estabelece a liberdade de aprender; no plano das liberdades públicas, a liberdade de aprender e de ensinar são corolários de uma visão democrática de mundo e devem ser garantidas no plano pedagógico, por todas as instituições.

Nenhum conflito existe entre esse princípio e a exigência de registro dos diplomas das IES não universitárias pelas Universidades, exigência essa de cunho administrativo e que visa unicamente atribuir validade nacional a esses documentos; o registro é uma exigência formal, a liberdade de ensinar é garantia material, relativa ao conteúdo do que é ensinado. Elas não são antinômicas e nem podem sê-lo, simplesmente pelo fato de que não se colocam no mesmo plano.

A alegação da inconstitucionalidade com base no disposto no artigo 209 esbarra em uma alegação ainda mais frágil. Esse dispositivo, como já várias vezes colocado neste texto, contém expressamente a necessidade de que o oferecimento dos serviços educacionais pela iniciativa privada só pode ocorrer se atendida a condição de cumprimento das normas gerais da educação. 
Frente a essa possível alegação a resposta será a mesma que já consta na parte inicial da resposta à questão colocada, e que é a resposta simples e objetiva de que a exigência do registro junto às universidades é uma norma geral da educação nacional e que, em razão disso deve ser obrigatoriamente cumprida por ser condição para o próprio funcionamento das IES privadas, segundo estabelece o inciso I do artigo 209 da Constituição Federal de 1988.

É necessário compreender que essa exigência possui objetivo de controle das atividades desenvolvidas pelas IES não universitárias, IES essas que não possuem autonomia. Esse sistema de controle via registro possibilita, entre outros, o controle do número de alunos concluintes (e, portanto, do número de vagas utilizado em comparação com o autorizado) e o cumprimento das diretrizes curriculares (pela conferência dos históricos escolares).

É ela uma exigência análoga aquela que ocorre com os registros públicos. As pessoas e as empresas possuem liberdade para realizar um grande conjunto de atos jurídicos, alguns por instrumento particular, outros por instrumento público. Entretanto, alguns desses atos só geram efetivamente direitos quando registrados nos órgão específicos (em algumas situações exige-se inclusive a homologação pelo Poder Judiciário - como ocorre na denominada jurisdição voluntária). Na organização da educação superior o poder competente - nesse caso o Poder Legislativo - atribuiu às Universidades a competência para esse registro. $E$ parece não existir qualquer base legal para questionar essa exigência.

Para não ficar adstrito à análise legal até agora enunciada, há, relativamente aos princípios da liberdade de ensinar e do controle público da educação, algumas análises mais liberais. Na sequência, tendo por base as posições de Victor Nunes Leal, constantes de parecer exarado em fevereiro de 1981, a pedido do Prof. Cândido Mendes, buscar-se-á verificar se adotando essa leitura é possível obter resultado diferente relativamente à questão colocada. Destaque-se desde logo que esse parecer foi elaborado sob a égide da Constituição de 1967/69, e que a aplicação de seu conteúdo ao texto da atual Constituição é uma construção hipotética.

Segundo Victor Nunes Leal, a leitura da Constituição Federal torna evidente que o ensino não se encontra entre as atividades privativas do Estado, que o ministraria de forma direta ou mediante concessão. Na atual Constituição isso fica claro da leitura da parte final do inciso III do artigo 206 do texto constitucional, ao estabelecer entre os princípios com base nos quais será ministrado o ensino, a "coexistência de instituições públicas e privadas".

Victor Nunes Leal destaca que o que ressalta da Constituição, mesmo em um exame inicial e superficial, é que "o ensino é livre à iniciativa privada" ${ }^{13}$. E "sendo o ensino uma atividade livre, fica de todo afastada a idéia de que possa conceituar-se como permitida ou concedida pelo poder público" ${ }^{14}$. Ou seja, no que se refere à atividade educacional, as instituições de ensino a exercem por direito próprio (embora precisem cumprir determinadas condições) - a legitimidade para esse exercício é inerente à sua própria personalidade jurídica.

Segundo Victor Leal Nunes: 
[...] torna-se evidente que o direito a ministrar o ensino não se origina de ato do poder público, mas emana, diretamente, da Constituição. O seu exercício é que pode ser fiscalizado e condicionado pelas autoridades. Mas é evidente que, não derivando esse direito do Estado [...], não pode a disciplina por lei impedir-Ihe o exercício, nem cerceá-lo ao ponto de conduzir a análogas conseqüências. Aqui, o essencial e substantivo é o direito; as restrições ou condições são o adjetivo ou circunstancial. ${ }^{15}$

Nesse sentido, embora o exercício do direito dependa de autorização administrativa $^{16}$, essa autorização não encerra uma deliberação discricionária, mas exprime apenas o juízo declaratório de estarem reunidos os pressupostos estabelecidos - no caso da atividade educacional, segundo os incisos I e II do artigo 209 da Constituição Federal, o "cumprimento das normas gerais da educação nacional" e a "avaliação de qualidade pelo Poder Público".

Ainda segundo Victor Leal Nunes:

[...] outro corolário de haver a Constituição liberado o ensino à iniciativa particular [art. 206, inciso III in fine; art. 209 capuf] é que a disciplina legal do seu exercício não pode ser tão apertada ou meticulosa que exclua as opções dos particulares, porque este é um traço inerente à liberdade de iniciativa. Um ensino maciçamente homogêneo, quer se trate de restrições diretas ou indiretas, ou tão circunscrito nas opções que os resultados sejam comparáveis, não pode ser tido como compatível com a Constituição. ${ }^{17}$

Adotando essa interpretação, o que se pode afirmar é que o controle público da educação é fundamental para a manutenção de sua qualidade. Entretanto, o exercício do controle público não pode afastar a liberdade de ensinar. O próprio texto constitucional, ao afirmar que o ensino é livre à iniciativa privada, também estabeleceu os requisitos a serem preenchidos. O controle público, nesse sentido, já possui seus contornos definidos constitucionalmente e deve ser exercido dentro desses limites.

Mesmo que se adote essa hipótese jurídica, nada se altera relativamente à exigência do registro dos diplomas. O que a análise de Victor Leal Nunes demonstra não é muito diferente do que havia sido anteriormente afirmado; ele apenas ressalta o princípio da liberdade de ensinar, atribuindo-Ihe uma conotação mais forte do que aquela assumida pelo autor deste texto. Mas em nenhum momento é possível entender que essa sua interpretação seja tão ampla a ponto de impedir o Estado de organizar o seu sistema educacional. O que ele afirma é que nessa organização o Estado não pode estabelecer normas que cerceiem a liberdade de ensinar, além daquelas que decorram diretamente das exigências constitucionais.

A norma que estabelece a necessidade do registro dos diplomas da IES não universitárias por Universidades em nada cerceia o direito de ensinar. Apenas estabelece uma condição para a validade nacional do diploma. Ou seja, mesmo essa leitura pró iniciativa privada não viabiliza uma interpretação no sentido de que o registro de diplomas possa ser realizado pelas próprias IES privadas não universitárias.

\section{CONSIDERAÇÕES FINAIS}


Tendo em vista o exposto neste texto, pode-se afirmar, de forma objetiva que:

a) as duas condições estabelecidas pela Constituição Federal (art. 209, inc. I e II), para o exercício da liberdade de ensinar, são o cumprimento das normas gerais da educação nacional, entendidas como as Leis que estabelecem as Diretrizes e Bases da Educação Brasileira e as demais normas educacionais previstas no texto constitucional ou que busquem implementar condições ou objetivos nele contidos; e a autorização e avaliação de qualidade pelo poder público, exercido na área educacional pelo Ministério da Educação. O controle público da educação deve ocorrer no acompanhamento do cumprimento dessas exigências;

b) a exigência do registro dos diplomados emitidos pelas IES não universitárias em Universidades credenciadas é estabelecida na LDB, principal Lei Federal que tem por objeto normas gerais da educação nacional;

c) a norma contida na LDB não fere nenhum princípio constitucional, nem mesmo o da liberdade de ensinar, tendo em vista que não coloca nenhuma restrição à essa atividade, mas apenas contém exigência de registro de documento para lhe atribuir validade nacional, sistema adotado no país para várias outros atos jurídicos;

d) a exigência de registro dos diplomas emitidos pelas IES não universitárias tem de ser cumprida, sob pena de não cumprimento de norma geral da educação nacional, o que pode levar ao descredenciamento da instituição, além de gerar sérios problemas para os egressos, cujos diplomas não terão validade nacional para fins de comprovação da formação; e

e) as IES não universitárias possuem liberdade no que se refere a escolha da Universidade na qual registrarão seus diplomas, mas esta escolha apenas pode ocorrer entre aquelas Universidades credenciadas pelo CNE.

\title{
CONTROL AND PUBLIC EDUCATION REGISTRATION COLLEGE DEGREE
}

\begin{abstract}
This article analyzes the constitutionality of granting the right to registration of qualifications for degree courses (undergraduate and post-graduate studies) exclusively with Universities. To achieve the objective, the work was divided into three stages, looking at each one, consider an aspect of the object studied. In the first carried out an analysis of the principles included in the Federal Constitution in relation to higher education, in particular the principles of freedom of teaching and public control of education. Following is appraised, the light of the constitution, the legislative authority to issue the general rules of national education. In a third and last time we analyze the assignment so that only the infra record the universities of higher education diplomas.
\end{abstract}

Keywords: Freedom to teach. Control of public education. University autonomy. Registration certificates. 


\section{NOTAS}

* Doutor e Mestre em Direito pela UFSC, com estágio de Pós-doutorado em Filosofia na UNISINOS. Professor Titular do Departamento de Direito da UFSC, lecionando no Curso de Graduação (Direito e Cidadania; Fundamentos da Educação Jurídica) e no Curso de Pós-graduação, nos Programas de Mestrado e Doutorado (Epistemologia Jurídica; Fundamentos e Metodologia do Ensino e da Pesquisa em Direito).

1. Que deve ser garantida, em nível pedagógico, pela definição de diretrizes curriculares flexíveis, que permitam o exercício dessa liberdade e, em nível administrativo, pela possibilidade de criação e manutenção de cursos, nas mais diversas áreas. Destaque-se que a autonomia para a criação é apenas das universidades, considerando que o artigo 209 expressamente contém como condição a ser atendida a autorização, exceção feitas às universidades, tendo em vista o contido no artigo 207 do texto constitucional.

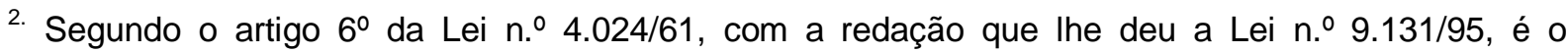
Ministério da Educação quem exerce, em matéria de educação, as atribuições do poder público federal.

3. Atualmente as normas gerais do sistema de avaliação encontram-se definidos pela Lei n.o 9.394/96 (LDB), em seu artigo 46, e pela Lei $n . .010 .861 / 2004$, que institui o SINAES - Sistema Nacional de Avaliação do Ensino Superior.

4. Sobre esse tema se retornará no item 3 deste artigo, quando da análise da competência normativa do Poder Executivo, em matéria educacional.

5. Conforme dispõe o artigo 205 da Constituição Federal de 1988.

6. Conforme dispõe o artigo 24, $\S \S 1^{\circ}$ e e $2^{\circ}$ da Constituição Federal de 1988.

7. No que se refere à solução das antinomias jurídicas - conflitos entre regras - o princípio fundamental aplicável, no âmbito do direito brasileiro, é o da hierarquia. Por esse critério, sempre que existirem duas normas educacionais em conflito, sendo elas hierarquicamente diferenciadas, a de hierarquia superior deve prevalecer sobre a de hierarquia inferior; sendo de mesma hierarquia, prevalecerá a especial em detrimento da geral; e sendo de mesma hierarquia e ambas especiais ou gerais, aplicar-se-á a mais recente. Entretanto, quando a colisão for de princípios, também chamada de antinomia jurídica imprópria, a solução deve ser encontrada pela aplicação do método da proporcionalidade, com a ponderação dos bens e valores envolvidos no caso específico.

${ }^{8}$. Normas corporativas, como o Estatuto da $\mathrm{OAB}$, mesmo que oriundas do parlamento, não são normas gerais da educação, devendo ter seu sentido necessariamente interpretado à luz dessas e, em especial, da Constituição Federal.

9. Conforme o artigo $2^{\circ}$ da Constituição Federal: "São Poderes da União, independentes e harmônicos entre si, o Legislativo, o Executivo e o Judiciário."

10. Essa observação guarda grande importância, tendo em vista que o emaranhado de Portarias, Resoluções e Decretos existentes nessa área nem sempre respeita o conteúdo material do texto constitucional e das Leis que estabelecem as Diretrizes e Bases da Educação Nacional - nessa situação a condição para o exercício da liberdade de ensino se encontra no cumprimento das normas hierarquicamente superiores, e não no cumprimento das disposições definidas pelo CNE ou pelo Ministério da Educação, através de seus diversos órgãos, quando contrariarem os princípios constitucionais e as normas gerais da educação brasileira. As demais normas, em especial Decretos, Resoluções e Portarias, apenas podem regulamentar essas normas gerais, jamais thes negar aplicação, não possuindo, quando o fizerem, validade material, devendo ser questionadas administrativa e judicialmente. O Poder Executivo, através do Ministério da Educação, exerce sim as atribuições do poder público federal, mas em nível executivo, cabendo-lhe zelar pelo cumprimento das normas gerais da educação nacional, na forma definida pelo parlamento. Suas atribuições, em nível normativo, se restringem à atividade necessária para a realização dos direitos e deveres definidos pela Assembléia Nacional Constituinte e pelo Congresso Nacional, o que deve ser efetivado através de Decretos (do Presidente da República), de Portarias (do Ministro) e de Resoluções (do Conselho Nacional de Educação). Tudo que exceder essas competências fere o sistema democrático presente no texto constitucional. A Constituição Federal e as normas gerais da educação brasileira não autorizam o Poder Público a negar direitos garantidos pela Assembléia Nacional Constituinte ou pelo Congresso Nacional. Isso significa que quando o Poder Público, através de Decretos, de Portarias, ou de Resoluções cria mecanismos que na prática impedem o exercício de qualquer direito, 
age inconstitucionalmente. O parlamento, quando edita normas que ferem o texto constitucional, age da mesma forma, não sendo as mesmas recepcionadas pelo sistema jurídico e cabendo ao Poder Judiciário, quando acionado, declarar a sua inconstitucionalidade.

11. A autorização do Poder Público, condição prevista na Constituição Federal para o exercício da liberdade de ensinar, na situação específica das Universidades se dá quando da autorização para que a Instituição de Ensino Superior (IES) passe para essa categoria. Uma vez autorizada a funcionar como Universidade, ela adquire autonomia para criar qualquer curso, em qualquer área do saber. $\mathrm{O}$ que cabe ao Poder Público, a partir de então, é a avaliação periódica da qualidade de ensino, sendo, portanto, inexigível, relativamente às Universidades, autorização prévia para a implementação de qualquer Curso ou para o aumento das vagas daqueles já existentes, quer pelo Poder Público quer por órgãos profissionais ou de área. A autonomia universitária está expressamente garantida no artigo 207 da Constituição Federal e no artigo 53 da LDB, sendo que este: (a) em seu inciso I lhes assegura a atribuição de, em sua sede, criar, organizar e extinguir cursos e programas de educação superior, desde que cumpridas as normas gerais da educação; (b) em seu inciso II, Ihes assegura autonomia para fixar os currículos de seus cursos e programas, desde que obedecidas as diretrizes gerais pertinentes; e (c) em seu inciso IV, Ihes assegura liberdade para fixar o número de vagas de seus cursos e programas, de acordo com a sua capacidade institucional e as exigências do seu meio.

12. Relativamente à condição insculpida no inciso II do artigo 209, de autorização e avaliação de qualidade pelo Poder Público, cabem as seguintes observações: (a) que a autorização e a avaliação aparecem ligadas, no texto, de forma absoluta, à expressão "de qualidade". Isso significa que não é qualquer autorização e nem qualquer avaliação, mas sim aquelas destinadas a analisar a qualidade do ensino proposto ou já ministrado; (b) que as condições de autorização e avaliação são relativas à qualidade, não podendo o Poder Público ou qualquer outro órgão criar exigências, especificamente para a autorização e avaliação, que não digam respeito ao elemento qualidade; e (c) que a presença dessa condição não pode ser vista como um deferimento ao Poder Público para agir de forma discricionária, simplesmente autorizando ou não o exercício daquilo que é um direito, mas sim como a necessidade de que, em nome da qualidade, sejam definidos parâmetros que, quando preenchidos, autorizem o seu exercício - qualquer decisão do poder público nessa matéria tem de ser motivada, com base no quesito qualidade. Em outras palavras, ao estabelecer essa condição o que a Constituição faz é dizer que a liberdade de ensinar pressupõe parâmetros qualitativos; definidos esses parâmetros, cabe ao Poder Público analisar cada pedido - preenchidos os parâmetros, deve ser concedida a autorização; não preenchidos, não pode ser concedida. De outro lado, através de mecanismos de avaliação periódica deve o Poder Público acompanhar a implementação das propostas aprovadas, podendo cancelar a autorização se a exigência de qualidade, de acordo com os parâmetros fixados, não estiver sendo cumprida.

${ }^{13}$. Na Constituição Federal de 1988, art. 209, caput.

14. NUNES, Victor Leal. Parecer. Rio de Janeiro: S. Ed., fevereiro de 1981.

15. Idem.

${ }^{16}$. Na Constituição Federal de 1988. art. 209, inc. II primeira parte.

17. NUNES. Op. Cit.

\section{REFERÊNCIAS}

BRASIL. Assembléia Nacional Constituinte. Constituição da República Federativa do Brasil de 1988.2 Disponível em: http://www.planalto.gov.br/ccivil_03/constituicao/constitui\%C3\%A7ao.htm. Acesso em: 30 jun. 2011.

BRASIL. Congresso Nacional. Lei n. 0 4.024/1961. Fixa as Diretrizes e Bases da Educação Nacional. [Revogada pela Lei oㅜ 9.394, de 1996, exceto os artigos 6ำ a 9oj.Disponível em: http://www.planalto.gov.br/ccivil_03/leis//4024.htm. Acesso em: 26 jul. 2011. 
. Lei n.o 8.069/1990. Estatuto da Criança e do Adolescente (ECA). Disponível em: http://www.planalto.gov.br/ccivil_03/leis//8069.htm. Acesso em: 26 jul. 2011.

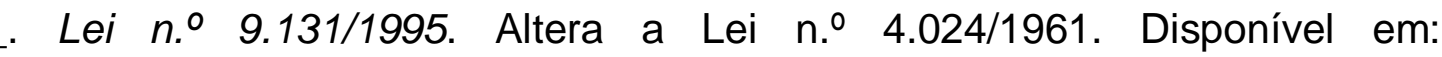
http://www.planalto.gov.br/ccivil_03/leis/19131.htm. Acesso em 26 jul. 2011.

. Lei.$^{\circ}$ 9.394/1996. Lei de Diretrizes e Bases da Educação Nacional (LDB). Disponível em: http://www.planalto.gov.br/ccivil_03/Leis/L9394.htm. Acesso em: 30 jun. 2011.

. Lei n. ${ }^{\circ}$ 9.536/1997. Regulamenta a transferência ex officio de Servidores Públicos Federais. Disponível em: http://www.planalto.gov.br/ccivil_03/leis/L9536.htm. Acesso em: 30 jun. 2011.

. Lei n. 9.795/1999. Dispõe sobre a Educação Ambiental. Disponível em: http://www.planalto.gov.br/ccivil_03/leis/19795.htm. Acesso em 26 jul. 2011.

. Lei n. ${ }^{0}$ 10.172/2001. Aprova o Plano Nacional de Educação. Disponível em: http://www.planalto.gov.br/ccivil_03/leis/leis_2001//10172.htm. Acesso em 26 jul. 2011.

Lei n. ${ }^{\circ}$ 10.741/2003. Estatuto do Idoso. Disponível em: http://www.planalto.gov.br/ccivil_03/leis/2003//10.741.htm. Acesso em: 30 jun. 2011.

. Lei n. 10.861/2004. Institui o Sistema Nacional de Avaliação da Educação Superior (SINAES). Disponível em: http://www.planalto.gov.br/ccivil_03/_ato20042006/2004/lei/l10.861.htm. Acesso em 26 jul. 2011. http://www.planalto.gov.br/ccivil_03/_ato2007-2010/2008/lei//11788.htm. Acesso em: 30 jun. 2011.

BRASIL. Conselho Nacional de Educação. Câmara de Ensino Superior. Parecer CNE/CES $\quad n .^{\circ}$ 165/2007. Disponível em: http://portal.mec.gov.br/cne/arquivos/pdf/2007/pces165_07.pdf. Acesso em: 30 jun. 2011.

NUNES, Victor Leal. Parecer. Rio de Janeiro: S. Ed., fev. 1981.

Recebido para publicação: 26/07/2011

Aceito para publicação: 13/12/2011 